\title{
Platelet and Blood Vessel Arachidonate
}

\section{Metabolism and Interactions}

\author{
Philip Needleman, Angela Wyche, and Amiram Raz, Department of Pharmacology, \\ Washington University Medical School, St. Louis, Missouri 63110
}

A B S T R A C T Exogenous arachidonate addition to intact platelets, in the absence or the presence of blood vessel microsomes, results in the production of thromboxane $B_{2}$ (the stable degradation product of thromboxane $\mathrm{A}_{2}$ ) only. Prostaglandin (PG) endoperoxides are released from intact platelets only when thromboxane synthetase is inhibited. Thus, addition of exogenous arachidonate to imidazole-pretreated platelets in the presence of bovine aorta microsomes (source of prostacyclin synthetase) results predominantly in the synthesis of 6-keto-PGF ${ }_{1 \alpha}$ (the stable degradation product of prostacyclin). Strips of intact aorta were removed from aspirin-treated rabbits, thus the isolated blood vessels were unable to convert endogenous or exogenous arachidonate to prostacyclin. Human platelets, with $\left[{ }^{14} \mathrm{C}\right]$ arachidonate-labeled phospholipids, adhered to the blood vessel segments and released some thromboxane $B_{2}$. The subsequent addition of thrombin facilitated the release of endogenous arachidonate and thromboxane, but no labeled 6-keto-PGF ${ }_{1 \alpha}$ was detectable. There is therefore no direct chemical evidence of PG-endoperoxide release from human platelets during either aggregation or adhesion, which therefore precludes the possibility that blood vessels use platelet PG-endoperoxide for prostacyclin synthesis. Imidazole inhibited the thromboxane synthetase in the labeled platelets, and thereafter thrombin stimulation resulted in the release of platelet-derived, labeled PG-endoperoxides that were converted to labeled prostacyclin by the vascular prostacyclin synthetase. The latter result suggests a potential antithrombotic therapeutic benefit might be achieved using an effective thromboxane synthetase inhibitor.

\section{INTRODUCTION}

Isolated intact blood vessels, arterial rings, or vascular homogenates have been demonstrated to convert small

Received for publication 10 November 1978 and in revised form 1 December 1978. amounts of arachidonic acid into prostacyclin $\left(\mathrm{PGI}_{2}\right)^{1}$ (1-3). However, vascular tissue quantitatively converts prostaglandin (PG) endoperoxides into $\mathrm{PGI}_{2}(4$, 5). In addition, indomethacin-treated blood vessel segments, stirred with platelet-rich plasma, prevent aggregation $(2,6)$. These data led to a hypothesis that advocates that endoperoxides are released from platelets during aggregation or adhesion and are used by the blood vessels to synthesize prostacyclin $(2,7,8)$. A homeostatic balance exists between thromboxane (the platelet-derived blood vessel contractor and platelet aggregator) and $\mathrm{PGI}_{2}$ (the vasodilator, antithrombotic substance produced by blood vessels). If plateletderived endoperoxides are in fact used by vasculature, then preferential synthesis of $\mathrm{PGI}_{2}$ over thromboxane would be anticipated. This hypothesis was supported by the observation that combination of lysed human platelets with lysed rat aortic smooth muscle cells increased the production of $\mathrm{PGI}_{2}$ from arachidonate, whereas platelets alone did not produce $\mathrm{PGI}_{2}(9)$. The current experiments were designed to provide direct chemical evidence regarding the ultimate fate of PGendoperoxides generated in intact platelets during aggregation or adhesion.

\section{METHODS}

$\left[{ }^{14} \mathrm{C}\right] P G H_{2}$. This was enzymatically synthesized and purified with acetone-pentane powder of sheep seminal vesicle microsomes as previously described $(10,11)$.

15-hydroperoxy-arachidonic acid. As an in vitro $\mathrm{PGI}_{2}$ synthetase inhibitor (12), this was synthesized enzymatically with soybean lipoxygenase and purified as previously described (13).

PG standards. $\mathrm{PGE}_{2}, \mathrm{D}_{2}, \mathrm{~A}_{2}, 6$-keto-PGF $\mathrm{F}_{1 \alpha}$, and thromboxane $B_{2}$ were kindly supplied by The Upjohn Co., Kalamazoo, Mich.

Bovine aorta microsomes (BAM). These were employed as

${ }^{1}$ Abbreviations used in this paper: A-9, solvent system employed to separate the $\mathrm{PGI}_{2}$ metabolite; BAM, bovine aorta microsomes; $\mathrm{BDA}$, solvent system employed to demonstrate the presence of thromboxane $B_{2} ; P G$, prostaglandin; $P_{2}$, prostacyclin. 
the source of $\mathrm{PGI}_{2}$ synthetase and were prepared from freshly dissected vessels. The arteries were minced, homogenized, and centrifuged for $10 \mathrm{~min}$ at $10,000 \mathrm{~g}$. The supernate was centrifuged for $60 \mathrm{~min}$ at $100,000 \mathrm{~g}$. The pellet was resuspended in $50 \mathrm{mM}$ phosphate buffer $(\mathrm{pH} 7.4)$ to yield a $4 \mathrm{mg} / \mathrm{ml}$ protein concentration and stored at $-70^{\circ} \mathrm{C}$.

Washed platelet preparation. Washed human platelet suspensions were prepared as previously described (14).

Platelet phospholipid labeling technique. Human blood was withdrawn into a syringe containing $1 / 13 \mathrm{vol}$ of $77 \mathrm{mM}$ EDTA. The erythrocytes were removed by centrifugation for $10 \mathrm{~min}$ at $120 \mathrm{~g}$ and the supernate was centrifuged at $4,000 \mathrm{~g}$ for $6 \mathrm{~min}$. The platelets were resuspended in $2 / 3 \mathrm{vol}$ of albumin-phosphate buffer ( $33 \mathrm{mM}, \mathrm{pH} 6.5$ ) containing $1 \mathrm{mg} /$ $\mathrm{ml}$ glucose, $6.6 \mathrm{mg} / \mathrm{ml} \mathrm{NaCl}$, and $5 \mathrm{mg} / \mathrm{ml}$ fatty acid poor bovine serum albumin. $\left[{ }^{14} \mathrm{C}\right]$ arachidonic acid $\left(2 \times 10^{6} \mathrm{cpm}\right)$, obtained from Amersham Corp., Arlington Heights, Ill. (55 $\mathrm{mC} / \mathrm{mmol}$ ), was dissolved in $100 \mu \mathrm{l}$ of Tris buffer $(100 \mathrm{mM}$, $\mathrm{pH}$ 9.0) and added to the platelet suspension that was incubated for $30 \mathrm{~min}$ at $37^{\circ} \mathrm{C}$. The labeled platelets were centrifuged at 2,000 RPM for $5 \mathrm{~min}$ and resuspended in calcium-free Krebs Henseleit media ( $\mathrm{pH}$ 7.4). Chromatographic analysis of the lipids extracted from these prelabeled platelets indicated that the incorporated radioactivity was primarily in the phosphatidyl choline and phosphatidyl ethanolamine fraction, with only trace amounts of free arachidonate detectable.

Extraction and chromatography. The reaction mixtures were acidified to $\mathrm{pH} 3.5$ with $2 \mathrm{~N}$ formic acid and extracted twice with 2 vol of ethyl acetate. The combined organic extract was dried over anhydrous $\mathrm{Na}_{2} \mathrm{SO}_{4}$, concentrated in a stream of $\mathrm{N}_{2}$, and applied together with unlabeled PG standards to silica gel $\mathrm{G}$ thin layer chromatography plates (Brinkman Instruments, Inc., Westbury, N. Y.). The solvent system (BDA) employed to demonstrate the presence of thromboxane $B_{2}$ was benzene:dioxane:acetic acid (60:30:3). The solvent system (A-9) employed to separate the $\mathrm{PGI}_{2}$ metabolite was the organic phase from ethyl acetate:acetic acid:2,2,4-trimethyl pentane:water (110:20:50:100) (15). The PG standards were visualized by iodine staining, the radioactive peaks were detected on a Vanguard Scanner (Packard Instrument Co., Downers Grove, Ill.).

\section{RESULTS}

Exogenous arachidonate metabolism by intact platelets and blood vessel microsomes. BAM were employed as a source of $\mathrm{PGI}_{2}$ synthetase to rapidly convert any available endoperoxide into $\mathrm{PGI}_{2}$. $\mathrm{PGI}_{2}$ decays to the stable metabolite 6 -keto-PGF ${ }_{1 \alpha}$, which is readily detected on thin layer chromatograms.

Washed human platelet suspensions rapidly converted $\left[{ }^{14} \mathrm{C}\right]$ arachidonic acid into thromboxane $B_{2}$ (Fig. 1A). There was no detectable shift in exogenous arachidonate metabolism when the intact platelets were combined with the blood vessel microsomes (Fig. 1B). These experiments indicate that the aggregating platelets were not releasing endoperoxides. Preincubation of the platelet suspensions with the thromboxane synthetase inhibitor imidazole $(16,17)$, before the addition of exogenous arachidonate, abolished the thromboxane $\mathrm{B}_{2}$ formation and resulted in the appearance of $\mathrm{PGE}_{2}$ and a trace of $\mathrm{PGD}_{2}$ (Fig. 1D). The $\mathrm{PGE}_{2}$ and $\mathrm{PGD}_{2}$ formation could have resulted either from the

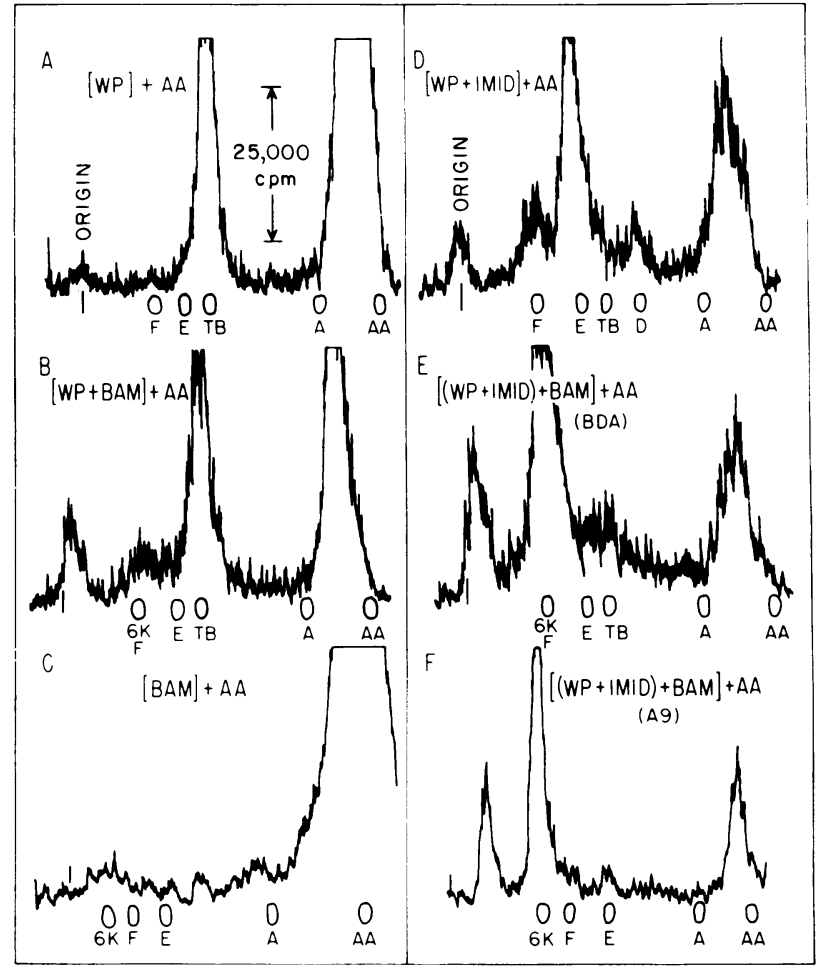

FIGURE 1 Arachidonate metabolism by human platelet suspensions in the presence or absence of blood vessel microsomes. Washed platelets (WP) $(0.4 \mathrm{ml})$ were incubated with $\left[{ }^{14} \mathrm{C}\right]$ arachidonic acid (AA) $(1 \mu \mathrm{g} ; 300,000 \mathrm{cpm})$ at $37^{\circ}$ with stirring in an aggregometer for $15 \mathrm{~min}$ and then extracted and chromatographed as described in Methods. The following additions were also made in the various experiments: BAM, $20 \mu \mathrm{l}(80 \mu \mathrm{g}$ protein); and imidazole $(5 \mathrm{mM})$ was preincubated 5 min with the platelets. In the BDA solvent system, 6-keto$\mathrm{PGF}_{1 \alpha}(6 \mathrm{~K})$ comigrates with $\mathrm{PGF}_{2 \alpha}(\mathrm{F})$, and in the A-9 solvent system, thromboxane $\mathrm{B}_{2}(\mathrm{~TB})$ comigrates with $\mathrm{PGE}_{2}(\mathrm{E})$. The chromatographs shown were separated in the BDA solvent system (i.e., A-E) except for $F$ which was separated in the A-9 system. All radiochromatograms were evaluated at the same gain setting on the Vanguard Scanner. The appropriate zones from the thin layer plate were scrapped, eluted, and counted, thus the TB spot in $2 \mathrm{~A}$ and $\mathrm{B}$ contains 46,779 and $42,816 \mathrm{cpm}$, respectively; the $\mathrm{E}$ zone in $2 \mathrm{D}$ contains 44,642 cpm, and the $6 \mathrm{~K}$ zone in $2 \mathrm{E}$ and $2 \mathrm{~F}$ contains $44,003 \mathrm{cpm}$. The origin is on the left of each scan and is indicated by a small vertical line.

nonenzymatic degradation of $\mathrm{PGH}_{2}$ (18) released from the platelets, or from the enzymatic activity of an isomerase. However, when exogenous arachidonate was added to a mixture of blood vessel microsomes and imidazole-treated platelets, the primary product was 6-keto-PGF ${ }_{1 \alpha}$ (Figs. $1 \mathrm{E}$ and $\mathrm{F}$ ). Thus, only when the intact platelets were prevented from forming thromboxane was there any extracellular endoperoxide available for the blood vessel microsomes to use as substrate for $\mathrm{PGI}_{2}$ synthesis.

Exogenous endoperoxide metabolism by platelets and blood vessel microsomes. BAM quantitatively 
converted exogenous $\mathrm{PGH}_{2}$ into 6-keto- $\mathrm{PGF}_{1 \alpha}$ (data not shown). The vascular $\mathrm{PGI}_{2}$ synthetase was readily inhibited by pretreatment with 15-hydroperoxy-arachidonic acid. When human platelet suspension was mixed with blood vessel microsomes, the primary $\mathrm{PGH}_{2}$ metabolite was 6-keto- $\mathrm{PGF}_{1 \alpha}$ (data not shown). Only when the vascular $\mathrm{PGI}_{2}$ synthetase was inhibited with the hydroperoxy fatty acid did the platelets convert endoperoxide to thromboxane. Thus, in mixing experiments of intact platelets and blood vessel microsomes, 6-keto-PGF ${ }_{1 \alpha}$ was the primary product formed from exogenous endoperoxide. In contrast, thromboxane $B_{2}$ was the primary product derived from intrinsic platelet $\mathrm{PGH}_{2}$.

$\mathrm{PGI}_{2}$ interactions between prelabeled platelets and intact blood vessels. Vascular microsomes lack membrane barriers that might prevent the penetration of the endoperoxide to the $\mathrm{PGI}_{2}$ synthetase. Furthermore, the above experiments analyzed the possibility of endoperoxide release during aggregation (i.e., platelet-toplatelet interaction). A different situation may occur during the adhesion reaction, i.e., platelet-to-blood vessel interaction.

Rabbit aorta were removed from animals $(n=4)$ pretreated for $2 \mathrm{~h}$ with $250 \mathrm{mg} / \mathrm{kg}$ aspirin. Thus, the intact aorta could not synthesize $\mathrm{PGI}_{2}$ from endogenous substrate or from any free $\left[{ }^{14} \mathrm{C}\right]$ arachidonate that might be in the medium. The phospholipids of washed platelets were labeled by incubating them with $\left[{ }^{14} \mathrm{C}\right]$ arachidonate in the presence of albumin. The labeled platelets were then incubated in the presence of the aspirintreated aorta segments. Under these circumstances, the only source for the vascular synthesis of $\left[{ }^{14} \mathrm{C}\right] 6$-keto$\mathrm{PGF}_{1 \alpha}$ is the $\left[{ }^{14} \mathrm{C}\right] \mathrm{PGH}_{2}$ from the labeled platelets. Control experiments indicated that the aspirin-treated rabbit aorta did not metabolize $\left[{ }^{14} \mathrm{C}\right]$ arachidonate but did convert $\left[{ }^{14} \mathrm{C}\right] \mathrm{PGH}_{2}$ into $\left[{ }^{14} \mathrm{C}\right] 6$-keto- $\mathrm{PGF}_{1 \alpha}$ (data not shown).

15 -min incubation of the labeled $(200,000 \mathrm{cpm})$ platelets alone did not result in any detectable arachidonate metabolism (Fig. 2A). Addition of rabbit aorta segments was followed by a rapid decrease in the opacity of the suspension of the labeled platelets, and extraction of the media indicated some thromboxane $\mathrm{B}_{2}$ formation and arachidonate (including hydroxy fatty acids) release (Fig. 2B). The aorta segments were removed after incubation with the platelets and were rinsed three times, blotted, and solubilized (Soluene, New England Nuclear, Boston, Mass.) for scintillation counting. $30 \%(61,000 \mathrm{cpm})$ of the radioactivity originally present in the labeled platelets was now tightly associated with the blood vessels, thereby indicating platelet-to-blood vessel adhesion.

Thrombin (Fig. 2C) or the calcium ionophore-A23187 (not shown) added 5 min after the labeled platelets and blood vessels were mixed facilitated the plate-

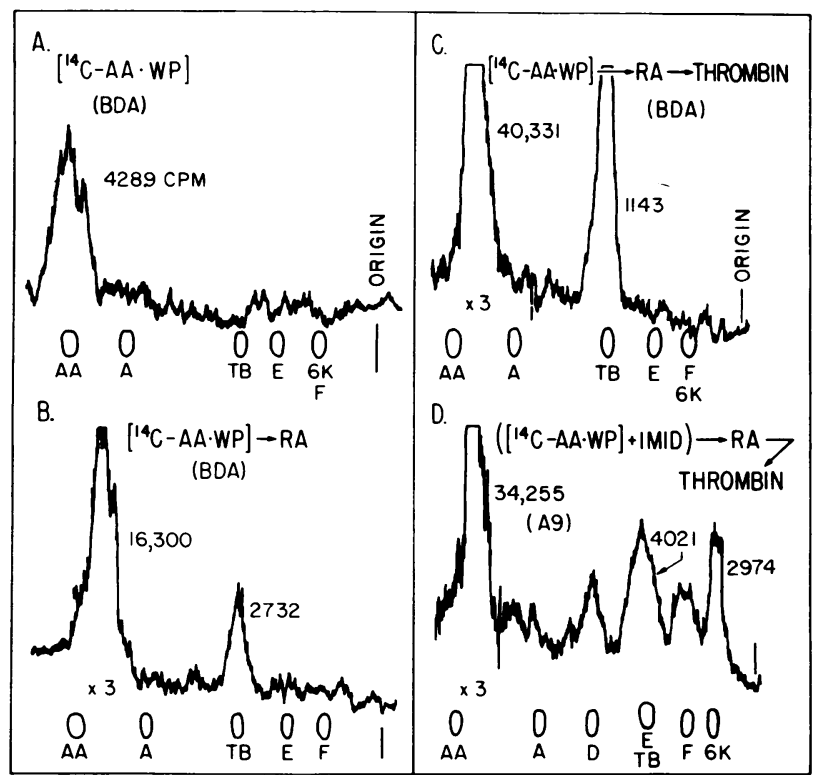

FIGURE 2 The metabolism of endogenous arachidonate by intact human platelets in the presence of intact blood vessels. The rabbit aorta (RA) segments were removed from aspirintreated $(250 \mathrm{mg} / \mathrm{kg}$ orally $2 \mathrm{~h}$ before removal) rabbits, cleaned free of adventitia, and sectioned. Four vessel segments (total wet weight of $60-100 \mathrm{mg}$ ) were added to $2 \mathrm{ml}$ of the prelabeled platelets (described in Methods). Thrombin (5 U) was used to stimulate platelet phospholipase activity. The release of radioactivity varied with the intensity of the response, thereby requiring different scanner gains. To quantitate the responses, the radioactive peaks were scrapped, eluted, and counted, and the numbers are indicated on the figure with the appropriate peak. The arachidonic acid (AA) present on scans $B, C$, and $D$ were so high that the gain of the scanner was reduced by a factor of 3 (indicated by $\times 3$ ). This representative experiment was repeated four times with comparable results.

let adhesion to the blood vessels (vascular radioactivity, $95,000 \mathrm{cpm}$ ), resulted in a pronounced release of $\left[{ }^{14} \mathrm{C}\right]$ arachidonate and $\left[{ }^{14} \mathrm{C}\right]$ thromboxane, but no labeled 6-keto-PGF ${ }_{1 \alpha}$ was detected (Fig. 2C). Thrombin has recently been shown to facilitate platelet adhesion to endothelial and vascular smooth muscle cells (19). Only when imidazole pretreatment blocked the platelet thromboxane synthetase was there any labeled substrate available for vascular (platelet adhesion was $\cong 50 \%$, i.e., $104,000 \mathrm{cpm}$ ) $\mathrm{PGI}_{2}$ synthesis (Fig. 2D). Comparable results were achieved when either aspirintreated rat aorta or bovine coronary artery were employed instead of rabbit aorta.

\section{DISCUSSION}

We have been unable to demonstrate evidence for endoperoxide release from platelets during either ag- 
gregation or adhesion, with either exogenous or endogenous arachidonate serving as substrate (Figs. 1-2). The same conclusion was recently drawn using a different experimental approach. Baenziger et al. (20) have incubated cultured, human, arterial, smooth muscle and venous, endothelial cells with human platelets in the presence of arachidonic acid and measured their $\mathrm{PGI}_{2}$ production by bioassay (i.e., inhibition of $\left[{ }^{14} \mathrm{C}\right]$ serotonin release from platelets). Significant $\mathrm{PGI}_{2}$ synthesis from platelet-derived cyclic endoperoxides by cultured cells pretreated with aspirin was observed only in the presence of imidazole, and was equivalent to $10-26 \%$ of the $\mathrm{PGI}_{2}$ production from arachidonic acid by cells not treated with aspirin. These studies confirm our finding that platelets make $\mathrm{PGH}_{2}$ available to cells of the vessel wall only when thromboxane synthetase is inhibited; the resultant $\mathrm{PGI}_{2}$ synthesis is considerably less than that available from endogenous arachidonic acid via the cyclooxygenase in smooth muscle or endothelial cells. The above data differ from those obtained when indomethacin-treated blood vessel rings inhibited aggregation when preincubated with platelet-rich plasma $(2,6-8)$. Our own experiments were not performed in plasma because the high levels of albumin would have precluded experiments with the labeled arachidonate. Other methods of analysis of PG end-products (e.g., immunoassay or mass spectrometry) would not have provided the opportunity to establish if the endoperoxide was of platelet origin. Furthermore, it has previously been shown that endoperoxides are extremely labile in albumin (18), thus even if a small amount of $\mathrm{PGH}_{2}$ was released from platelets it would not be expected to be converted to $\mathrm{PGI}_{2}$.

Abolition of vascular $\mathrm{PGI}_{2}$ synthesis would conceivably lead to the release of $\mathrm{PGH}_{2}$ which could be converted to thromboxane by adherent platelets. Such a reverse exchange of endoperoxide has not been demonstrated in intact tissues. However, inhibition of vascular $\mathrm{PGI}_{2}$ synthesis, either by tranylcypromine or by high doses of aspirin, have been found to significantly augment thrombus size (21). In sharp contrast, when platelets inhibited with thromboxane synthetase inhibitors (or lysed platelets) adhere to blood vessels, an exchange of endoperoxide (without exposure to plasma) between the two cell types would be expected to occur (Figs. $1 \mathrm{~F}$ and 2D), ultimately resulting in $\mathrm{PGI}_{2}$ production and inhibition of local platelet aggregation. Platelet membrane is reported to remain intact after adhesion to vascular tissue (22) normally precluding an opportunity for endoperoxide release from platelets. These results reinforce the potential therapeutic benefit that would be achieved with a clinically effective thromboxane synthetase inhibitor.

Finally, some controversy exists about the ability of PG-endoperoxides to penetrate cell membranes to the
$\mathrm{PGI}_{2}$ synthetase. Intact cultured endothelial cells have been demonstrated to convert exogenous $\mathrm{PGH}_{2}$ into $\mathrm{PGI}_{2}(23,24)$, whereas isolated perfused rabbit hearts do not (25). In agreement with the latter observation, $\mathrm{PGI}_{2}$ synthesis was stimulated by treatment of a perfused rabbit mesenteric vascular bed with exogenous arachidonate or angiotensin II (which releases endogenous arachidonate), but not by exogenous $\mathrm{PGH}_{2}(26)$. Furthermore, when the endothelium of the mesenteric vasculature was completely denuded by hypotonic shock, the arachidonate and the angiotensin still produced comparable levels of $\mathrm{PGI}_{2}$, indicating the effectiveness of the subendothelial vascular smooth muscle in synthesizing $\mathrm{PGI}_{2}$. The lack of evidence of PG endoperoxide release from intact platelets (at levels that we can detect, i.e., $\leqq 1 \%$ total radioactivity) coupled with the apparent inability of numerous intact vascular tissues to convert $\mathrm{PGH}_{2}$ into $\mathrm{PGI}_{2}$ therefore seems to compromise the hypothesis that blood vessels use platelet PG endoperoxides for $\mathrm{PGI}_{2}$ synthesis.

\section{ACKNOWLEDGMENTS}

This work was supported by National Institutes of Health grants HL-20787, contract HV-72945, and SCOR-HL-17646.

\section{REFERENCES}

1. Moncada, S., R. Gryglewski, S. Bunting, and J. R. Vane. 1976. An enzyme isolated from arteries transforms prostaglandin endoperoxides to an unstable substance that inhibits platelet aggregation. Nature (Lond.). 263: 633-635.

2. Bunting, S., R. Gryglewski, S. Moncada, and J. R. Vane. 1976. Arterial walls generate from prostaglandin endoperoxides a substance (prostaglandin $\mathrm{X}$ ) which relaxes strips of mesenteric and coeliac arteries and inhibits platelet aggregation. Prostaglandins. 12: 897-915.

3. Kulkarni, P. S., R. Roberts, and P. Needleman. 1976. Paradoxical endogenous synthesis of a coronary dilating substance from arachidonate. Prostaglandins. 12: 337-353.

4. Dusting, G. J., S. Moncada, and J. R. Vane. 1977. Prostaglandin (PGX) is the endogenous metabolite responsible for relaxation induced by arachidonic acid. Prostaglandins. 13: 3-16.

5. Raz, A., P. C. Isakson, M. S. Minkes, and P. Needleman. 1977. Characterization of a novel metabolic pathway of arachidonate in coronary arteries which generates a potent endogenous coronary vasodilator. J. Biol. Chem. 252: 1123-1126.

6. Moncada, S., E. A. Higgs, and J. R. Vane. 1977. Human arterial and venous tissues generate prostacyclin (prostaglandin $\mathrm{X}$ ), a potent inhibitor of platelet aggregation. Lancet. I: 18-20.

7. Bunting, S., S. Moncada, and J. R. Vane. 1977. Antithrombotic properties of vascular endothelium. Lancet. II: $1075-1076$.

8. Moncada, S., and J. R. Vane. 1978. Unstable metabolites of arachidonic acid and their role in hemostasis and thrombosis. Br. Med. Bull. 34: 129-135.

9. Tansik, R. L., D. H. Namm, and H. L. White. 1978. Synthesis of prostaglandin 6-Keto $F_{1 \alpha}$ by cultured aortic smooth muscle cells and stimulation of its formation by a coupled 
system with platelet lysates. Prostaglandins. 15: 399408.

10. Needleman, P., M. Minkes, and A. Raz. 1976. Thromboxanes: selective biosynthesis and distinct biological properties. Science (Wash. D. C.). 193: 163-165.

11. Gorman, R. R., F. F. Sun, O. V. Miller, and R. A. Johnson. 1977. Prostaglandins $H_{1}$ and $H_{2}$. Convenient biochemical synthesis and isolation. Further biological and spectroscopic characterization. Prostaglandins. 13: 1043-1056.

12. Moncada, S., R. J. Gryglewski, S. Bunting, and J. R. Vane. 1976. A lipid peroxide inhibits the enzyme in blood vessel microsomes that generates from prostaglandin endoperoxides the substance which prevents platelet aggregation. Prostaglandins. 12: 715-738.

13. Funk, M. O., R. Isaac, and N. A. Porter. 1976. Preparation and purification of lipid hydroperoxides from arachidonic and linolenic acids. Lipids. 11: 113-117.

14. Minkes, M., N. Stanford, M. Chi, G. J. Roth, A. Raz, P. Needleman, and P. W. Majerus. 1977. Cyclic adenosine 3',5'-monophosphate inhibits the availability of arachidonate to prostaglandin synthetase in human platelet suspensions. J. Clin. Invest. 59: 449-454.

15. Hamberg, M., and B. Samuelsson. 1966. Prostaglandins in human seminal plasma. J. Biol. Chem. 241: 257-263.

16. Needleman, P., A. Raz, J. A. Ferrendelli, and M. S. Minkes. 1977. Application of imidazole as a selective inhibitor of thromboxane synthetase in human platelets. Proc. Natl. Acad. Sci. U. S. A. 74: 1716-1720.

17. Moncada, S., S. Bunting, K. Mullan, P. Thorogood, J. R. Vane, A. Raz, and P. Needleman. 1977. Imidazole: a selective inhibitor of thromboxane synthetase. Prostaglandins. 13: $611-620$.

18. Hamberg, M., and B. B. Fredholm. 1976. Isomerization of $\mathrm{PGH}_{2}$ into $\mathrm{PGD}_{2}$ in the presence of serum albumin. Biochim. Biophys. Acta. 431: 189-193.
19. Czervionke, R. L., J. C. Hoak, and G. L. Fry. 1978. Effect of aspirin on thrombin-induced adherence of platelets to cultured cells from the blood vessel wall.J. Clin. Invest. 62: 847-856.

20. Baenziger, N. L., P. R. Becherer, and P. W. Majerus. 1978. $\mathrm{PGI}_{2}$ production in cultured human arterial smooth muscle cells, venous endothelial cells, and skin fibroblasts. Relative levels, pathway of synthesis, and aspirin inhibition. Cell. In press.

21. Kelton, J. G., J. Hirsh, C. J. Carter, and M. R. Buchanan. 1978. Thrombogenic effect of high dose aspirin in rabbits. Relationship to inhibition of vessel wall synthesis of prostaglandin $\mathrm{I}_{2}$-like activity. J. Clin. Invest. 62: 892895.

22. Baumgartner, H. R., and R. Muggli. 1976. Adhesion and aggregation morphological demonstration and quantitation in vivo and in vitro. In Platelets in Biology and Pathology. J. L. Gordon, editor. Elsevier, North Holland Biomedical Press. 23-41.

23. Weksler, B. B., A. J. Marcus, and E. A. Jaffe. 1977. Synthesis of prostaglandin $I_{2}$ (prostacyclin) by cultured human and bovine endothelial cells. Proc. Natl.Acad.Sci.U.S.A. 74: 3922-3926.

24. Moncada, S., A. G. Herman, E. A. Higgs, and J. R. Vane. 1977. Differential formation of prostacyclin (PGX or $\mathrm{PGI}_{2}$ ) by layers of the arterial wall. An explanation for the antithrombotic properties of vascular endothelium. Thromb. Res. 11: 323-344.

25. Needleman, P., S. D. Bronson, A. Wyche, M. Sivakoff, and K. C. Nicolaou. 1978. Cardiac and renal prostaglandin $I_{2}$. Biosynthesis and biological effects in isolated perfused rabbit tissues. J. Clin. Invest. 61: 839-849.

26. Pure, E., and P. Needleman. 1979. The effect of endothelial damage on prostaglandin synthesis by the isolated perfused rabbit mesenteric vasculature. In press. 